\title{
Statistical parameters of the properties of agro-gray soils in the Northern part of the forest-steppe
}

\author{
Lilia Gaffarova* and Albina Serzhanova \\ Kazan State Agrarian University, 420015 Kazan, Republic of Tatarstan, Russia
}

\begin{abstract}
The paper analyzes the regional statistical characteristics of analytical and morphometric properties of agro-gray soils formed in one-factor conditions of the Privyatskaya band of the Pre-Kama region of the Republic of Tatarstan. The sampling of analytical data was carried out in accordance with the systematic group and non-eroded soil analogues. The upper part of the soil profile of the studied soil has a low humus content, medium acid reaction, the profile distribution of the sum of absorbed bases is almost uniform and is in the range of 22.6 to $26.8 \mathrm{mmol} / 100 \mathrm{~g}$ of soil. Generalization of the accumulated analytical and morphological information is a zero cycle of monitoring of arable soils and can serve as a reference for comparison to identify changes in the properties and morphological structure of arable soils in the region. In conditions of intensive agriculture, statistical parameters make it possible to purposefully manage soil fertility in the studied region.
\end{abstract}

\section{Introduction}

Agrogenic effects cause changes in various properties, ranging from genetic horizons to the availability of soil nutrients for plants. Natural processes differ in speed, rate of flow from the type and subtype of ownership. To obtain accurate analytical information, it is necessary to constantly monitor the state of soil properties and the morphological structure of arable soils in the region, which is an objective basis for the rational use of soil resources.

Plowing of natural virgin soils and their use in agriculture completely violate the upper horizons of the soil, in some cases it slows down natural processes, such as the process of creating sod, in other cases, on the contrary, it accelerates the processes. Under arable land, the oxidative processes of subsequent plant residues are activated, and humus mineralization occurs faster due to improved air conditions [1].

Intensive agriculture being developed in the Republic of Tatarstan is based on creating optimal soil properties, increasing the moisture capacity and nutrition elements of the arable horizon to create good conditions for the growth and development of cultivated plants.

Research has shown that each type of soil is characterized by a specific complex that has the greatest impact on the productivity of a certain group of cultivated plants [2].

However, there are significant differences in soil fertility in a particular soil-climate zone and within a single variety. The values of a large sample of parameters will allow a more accurate assessment of the state of soil fertility in any territory.
The leading role in creating a favorable soil environment for plants belongs to properties characterizing the degree of acidity of soils, the reserves of humus, the state of the Soil absorbing complex, the content of mobile forms of phosphorus and potassium. Assessment of the current state of soils is possible via their statistical parameters obtained on the basis of a representative sample [3-6].

The soil, as a natural body formed on the outer layer of the Earth' $s$ crust under the influence of various factors. It undergoes changes both in space and in time, which determines the possibility of using mathematical methods for processing soil indicators and morphometric measurements.

Soil properties and parameters of genetic horizons change over time. This circumstance determines the significance of statistical parameters and their ability to be considered as indicators of the so-called "zero" cycle of soil monitoring.

\section{Materials and research methods}

Lists of values of soil characteristics and properties were compiled for heavy-loam varieties of soil in the context of genetic horizons. The lower limit of genetic horizons, soil properties (humus content, physical clay (particles $<0.01$ and $<0.001 \mathrm{~mm}$ ), the sum of absorbed bases and hydrolytic acidity in mmol/100 $\mathrm{g}$ of soil, $\mathrm{pH}$ of salt suspension) are analyzed.

The existing experience of processing actual data using standard mathematical and statistical methods of analysis and pre-processing of the sample allows us to assess the dynamic and stable properties of soils and the state of their level of fertility $[7,8]$.

* Corresponding author: gaffarovalylya@mail.ru 
The object of research is agro-gray (Grey-Luvic PHAEOZEMS, WRB) soils [9] of the right - Bank part Of the Vyatka strip of the pre-Kama Region with a total area of 713.5 thousand hectares (including 403.6 thousand hectares of arable land). Here they are zonal soils $-52 \%$ of the area.

To create statistical models of the last object, the materials of a large-scale soil survey with the creation of a data bank were used. Their soil-forming rocks were deluvial deposits.

Parameters of soil properties characterize the state of agro-gray soils over the past 15-30 years.

The following limits are obtained using mathematical statistics: maximum and minimum values, arithmetic averages $(M)$ and their errors $( \pm m)$, mean square deviations $(\sigma)$, coefficient of variation $(\mathrm{V})$, accuracy index $(\mathrm{P}, \%)[3]$.

\section{Research results}

Genetic horizons and their distribution along the profile are a fundamental feature, reflecting all the soil processes that take place in the history of each soil. Accordingly, the presented material with their statistical indicators is a "zero" cycle of soil monitoring in the studied region.

Statistical parameters of morphological features and soil properties are considered as exemplified by agro gray heavy loamy soils of the Privyatskaya band of the Pre-Kama RTB presented in table 1.

Humic substances, usually most of them, are associated with the mineral part of the soil and are present in fractions of fine dust and silt [7]. The humus content in the arable horizon is low. Below the arable horizon, the amount of humus decreases along the profile relatively smoothly. So, in the arable horizon it contains $4.0 \%$, and in the transition horizons $2.2-2.3 \%$ of humus.

Table 1. Statistical indicators of grey forests heavy loam arable soils, $\%$

\begin{tabular}{|c|c|c|c|c|c|c|c|c|}
\hline Horizon & $n$ & $\max$ & $\min$ & M & $\sigma$ & $\pm \mathrm{m}$ & $\mathrm{V}, \%$ & $\mathrm{P}, \%$ \\
\hline \multicolumn{9}{|c|}{ Humus, $\%$} \\
\hline $\mathrm{P}$ & 99 & 6.2 & 2.8 & 4.0 & 0.76 & 0.08 & 19.1 & 1.9 \\
\hline AEL & 29 & 3.7 & 1.1 & 2.2 & 0.77 & 0.14 & 34.8 & 6.5 \\
\hline BEL & 40 & 3.8 & 1.0 & 2.3 & 0.79 & 0.12 & 35.8 & 5.7 \\
\hline $\mathrm{BT}_{1}$ & 86 & 2.5 & 0.1 & 0.8 & 0.32 & 0.03 & 37.5 & 4.0 \\
\hline $\mathrm{BT}_{2}$ & 28 & 1.1 & 0.3 & 0.6 & 0.18 & 0.03 & 30.4 & 5.7 \\
\hline \multicolumn{9}{|c|}{ The content of physical clay particles $(<0.01 \mathrm{~mm}), \%$} \\
\hline $\mathrm{P}$ & 90 & 50.6 & 37.7 & 44.3 & 3.33 & 0.35 & 7.5 & 0.8 \\
\hline AEL & 33 & 62.8 & 38.1 & 46.7 & 6.12 & 1.07 & 13.1 & 2.3 \\
\hline BEL & 33 & 60.6 & 36.8 & 47.1 & 6.90 & 1.20 & 14.6 & 2.5 \\
\hline $\mathrm{BT}_{1}$ & 86 & 70.5 & 37.6 & 51.3 & 6.96 & 0.75 & 13.6 & 1.5 \\
\hline $\mathrm{BT}_{2}$ & 62 & 69.6 & 39.2 & 54.2 & 6.03 & 0.77 & 11.1 & 1.4 \\
\hline BC & 32 & 75.0 & 24.6 & 51.2 & 10.02 & 1.77 & 19.5 & 3.4 \\
\hline $\mathrm{C}$ & 57 & 75.0 & 24.6 & 51.2 & 10.20 & 1.35 & 19.5 & 2.6 \\
\hline \multicolumn{9}{|c|}{ Content of silt particles $(<0.001 \mathrm{~mm}), \%$} \\
\hline $\mathrm{P}$ & 90 & 25.9 & 11.8 & 19.0 & 3.38 & 0.36 & 17.8 & 1.8 \\
\hline AEL & 33 & 37.2 & 15.7 & 23.5 & 6.20 & 1.08 & 26.4 & 4.6 \\
\hline BEL & 33 & 38.9 & 9.9 & 21.5 & 7.30 & 1.27 & 34.0 & 5.9 \\
\hline $\mathrm{BT}_{1}$ & 86 & 46.6 & 10.6 & 31.2 & 7.68 & 0.83 & 24.6 & 2.6 \\
\hline $\mathrm{BT}_{2}$ & 62 & 45.6 & 20.2 & 35.4 & 5.96 & 0.76 & 16.8 & 2.4 \\
\hline $\mathrm{BC}$ & 32 & 41.3 & 20.0 & 34.7 & 5.62 & 0.99 & 16.2 & 2.9 \\
\hline $\mathrm{C}$ & 57 & 44.6 & 17.6 & 31.5 & 6.77 & 0.90 & 21.5 & 2.8 \\
\hline \multicolumn{9}{|c|}{ Amount of absorbed bases, $\mathrm{mmol} / 100 \mathrm{~g}$ of soil } \\
\hline $\mathrm{P}$ & 91 & 39.2 & 17.7 & 25.4 & 4.80 & 0.50 & 7.4 & 0.8 \\
\hline AEL & 28 & 35.1 & 14.9 & 22.6 & 4.20 & 0.79 & 18.6 & 3.5 \\
\hline BEL & 39 & 41.8 & 16.8 & 25.1 & 6.40 & 1.03 & 25.6 & 4.1 \\
\hline $\mathrm{BT}_{1}$ & 83 & 36.7 & 15.8 & 25.2 & 4.70 & 0.52 & 18.7 & 2.0 \\
\hline $\mathrm{BT}_{2}$ & 34 & 38.5 & 17.0 & 26.8 & 4.10 & 0.70 & 15.3 & 2.6 \\
\hline \multicolumn{9}{|c|}{ Hydrolytic acidity, mmol/100 $\mathrm{g}$ of soil } \\
\hline $\mathrm{P}$ & 66 & 8.1 & 0.7 & 3.4 & 1.58 & 0.20 & 46.5 & 5.7 \\
\hline AEL & 17 & 7.9 & 1.0 & 3.2 & 1.70 & 0.41 & 53.3 & 12.9 \\
\hline BEL & 21 & 4.2 & 0.5 & 2.3 & 1.07 & 0.23 & 46.8 & 10.2 \\
\hline $\mathrm{BT}_{1}$ & 40 & 4.3 & 0.7 & 2.4 & 0.94 & 0.15 & 39.7 & 6.3 \\
\hline \multicolumn{9}{|c|}{$\mathrm{pH}$ of salt and water suspension } \\
\hline $\mathrm{P}$ & 97 & 6.8 & 4.4 & 5.4 & 0.52 & 0.05 & 9.5 & 1.0 \\
\hline AEL & 27 & 6.9 & 4.5 & 5.4 & 0.62 & 0.12 & 11.6 & 2.2 \\
\hline BEL & 31 & 6.5 & 4.9 & 5.5 & 0.54 & 0.10 & 9.7 & 1.7 \\
\hline $\mathrm{BT}_{1}$ & 85 & 6.7 & 4.0 & 5.2 & 0.62 & 0.07 & 11.8 & 1.7 \\
\hline $\mathrm{BT}_{2}$ & 60 & 6.3 & 3.6 & 5.0 & 0.56 & 0.07 & 11.1 & 1.4 \\
\hline BC & 37 & 8.5 & 4.3 & 6.8 & 1.34 & 0.22 & 19.7 & 3.0 \\
\hline $\mathrm{C}$ & 52 & 8.6 & 4.1 & 6.7 & 1.54 & 0.21 & 23.2 & 3.2 \\
\hline
\end{tabular}


In modern agriculture of the Republic of Tatarstan, the annual loss of humus is about $1.8 \mathrm{t} / \mathrm{ha}$. Due to the receipt of crop and root residues, the accumulation of humus is $1.24 \mathrm{t} / \mathrm{ha}$, due to organic residues $-0.09 \mathrm{t} / \mathrm{ha}$, perennial grasses -0.04 , the use of straw -0.12 and siderates $-0.01 \mathrm{t} / \mathrm{ha}$. The annual deficit to the equilibrium balance is $0.30 \mathrm{t} / \mathrm{ha}$ [5]. In the illuvial horizon, the proportion of humus is $0.8 \%$, which indicates that this type of soil represents a transition to the black earth type of soil formation.

The content of physical clay of the upper soil horizons belongs to the heavy-loam variety, it ranges from 44.3 to $47.1 \%$ (table 1 ).

In the illuvial horizon and soil-forming rock, the content of physical clay increases, becoming more than $50+\%$, which corresponds to the clay granulometric composition. The variation coefficients change in a small range - from 7.5 to $19.5 \%$, since the particle content $(<0.01 \mathrm{~mm})$ is related to the fundamental soil properties.

The soil profile contains silt from 19.0 to $35.4 \%$ (table. 2) with minimum values for the upper arable horizon formed as a result of mixing of humusaccumulative and transitional AEL and BEL horizons, and maximum values characteristic of the illuvial horizon B. Since the silt fraction is more mobile than physical clay, the level of coefficients of variation of the silt fraction is higher $-16.2-34.0 \%$.

Only in the arable horizon, the silt content is $42.9 \%$. In horizon $\mathrm{B}$, the silt content in physical clay reaches $65.3 \%$. This differentiation of the proportion of silt fraction content in the composition of physical clay indicates the predominance of the eluvial process over the illuvial in the arable horizon, and vice versa, the process of illuvation - in the subhorizons.

The obtained correlation coefficients between the content of silt fraction and physical clay in the genetic horizons of gray forest soil also confirm the existence of a connection between them. The correlation coefficients vary in the range of $0.436-0.851$ (table 2). Meanwhile, high, statistically reliable coefficients indicate that the processes of destruction, movement of particles down the profile, and, finally, the process of their accumulation in the illuvial horizon are characterized by a relatively uniform speed.

The profile distribution of the amount of absorbed bases is almost uniform and ranges from 22.6 to 26.8 $\mathrm{mmol} / 100 \mathrm{~g}$ of soil (table 1$)$. Relatively low and average coefficients of variation $(7.4-25.6 \%)$ confirm the possibility of their attribution to stable soil properties.

Table 2. Parameters of correlation between the content of particles $<0.01(\mathrm{x})$ and $<0.001$ (y) in the gray forest heavy loam arable soil

\begin{tabular}{|c|c|c|c|c|c|}
\hline \multicolumn{2}{|c|}{ Properties } & \multirow{2}{*}{$n$} & \multirow{2}{*}{$r$} & \multicolumn{2}{|c|}{ Regression equation } \\
\cline { 5 - 6 } \cline { 5 - 5 } & & $\mathrm{y}$ & & $\mathrm{x}=\mathrm{a} \cdot \mathrm{y}+\mathrm{B}$ & $\mathrm{y}=\mathrm{a} \cdot \mathrm{x}+\mathrm{B}$ \\
\hline $\mathrm{P}$ & $\mathrm{P}$ & 90 & 0.436 & $\mathrm{x}=0.4303 \cdot \mathrm{y}+36.11$ & $\mathrm{y}=0.4424 \cdot \mathrm{x}-0.61$ \\
\hline $\mathrm{AEL}$ & $\mathrm{AEL}$ & 33 & 0.796 & $\mathrm{x}=0.7862 \cdot \mathrm{y}+28.26$ & $\mathrm{y}=0.8060 \cdot \mathrm{x}-14.18$ \\
\hline $\mathrm{BEL}$ & $\mathrm{BEL}$ & 86 & 0.851 & $\mathrm{x}=0.8047 \cdot \mathrm{y}+29.82$ & $\mathrm{y}=0.9002 \cdot \mathrm{x}-20.93$ \\
\hline $\mathrm{BT}_{1}$ & $\mathrm{BT}_{1}$ & 62 & 0.828 & $\mathrm{x}=0.7508 \cdot \mathrm{y}+27.90$ & $\mathrm{y}=0.9132 \cdot \mathrm{x}-15.67$ \\
\hline $\mathrm{BC}$ & $\mathrm{BC}$ & 32 & 0.814 & $\mathrm{x}=1.5113 \cdot \mathrm{y}+2.28$ & $\mathrm{y}=0.4387 \cdot \mathrm{x}+10.68$ \\
\hline $\mathrm{C}$ & $\mathrm{C}$ & 57 & 0.815 & $\mathrm{x}=1.2046 \cdot \mathrm{y}+13.34$ & $\mathrm{y}=0.5511 \cdot \mathrm{x}+3.22$ \\
\hline
\end{tabular}

$\mathrm{N}$ o te. The critical values of the correlation coefficient at the significance level $\alpha=0.05$ and $n=32$ are equal to 0.35 .

In the region, there is a periodic washing type of water regime, which leads to acidification of the upper soil horizons (see table 3 ). Hydrolytic acidity in the upper horizons has higher values (from 3.2 to $3.4 \mathrm{mmol} / 100 \mathrm{~g}$ of soil) than in the lower ones $(2.3-2.4$ $\mathrm{mmol} / 100 \mathrm{~g}$ of soil).

Indicators of hydrolytic acidity belong to the group of mobile properties, and therefore the change in the coefficients of variation is significant (39.7-53.3\%). Although soil acidity is a fundamental property, it changes over time when soils are used in intensive farming. The main operating factors are the washing mode and the use of mineral fertilizers.

The upper part of the soil profile and the illuvial horizons of gray forest soils have a medium-acid and slightly acidic reaction of the medium, the $\mathrm{pH}$ of the salt extract is from 5.0 to 5.5 (table 1). And only the transition to the rock horizon and the soil-forming rock have a neutral environment. The change in $\mathrm{pH}$ values in the profile is comparable to the morphometry and composition of the absorbed bases. The coefficients of variation are distributed unevenly across the profile with increasing values in the soil-forming rock (9.5-23.2\%).

The soils of the Republic of Tatarstan have a positive balance of nitrogen and phosphorus, and a negative balance of potassium, that is, its alienation with the crop yield exceeds the replenishment due to fertilizers $[5,6]$. Due to the dynamism of the content of mobile phosphorus and exchange potassium, their statistical parameters are not analyzed.

Typical values of soil properties are a diagnostic sign of both the type of soil belonging and the results of economic activity. Typical values of properties, their range also indirectly reflects the amount of work to be done to reproduce the soil fertility of arable land, and their upper limit can serve as a guideline for this purpose, since they reflect $50 \%$ of the total sample and, accordingly, of the occupied area.

Gray forest soils are mainly represented by heavyloam varieties that occupy gentle slopes, as well as flat areas [12]. The arable horizon of these soils is formed by O-AY-AEL and partially BEL horizons. As a rule, the transition horizon BEL is located under the processed layer. Statistical parameters of grey forest arable soils are similar in many respects to the data of the more Northern subtype of light grey forest soils. The content of physical clay indicates a heavy granulometric composition. Thus, typical values in the arable horizon have ranges of $42.0-46.6 \%$, and in the sub-arable horizon it is slightly wider-42.6-51.9\% (table 3).

\footnotetext{
* Corresponding author: gaffarovalylya@mail.ru
} 
Table 3. Typical values of the lower boundary of horizons $(\mathrm{cm})$ and properties in gray forest arable soils.

\begin{tabular}{|c|c|c|c|c|c|c|c|}
\hline Property & $\mathrm{n}$ & Limit value & $\mathrm{M}$ & $\sigma$ & $\mathrm{Q}_{0.50}$ & $\mathrm{~V}_{\min }$ & $\mathrm{V}_{\max }$ \\
\hline \multicolumn{8}{|c|}{ Fundamental property } \\
\hline $\mathrm{P}, \mathrm{cm}$ & 90 & $18-30$ & 24.5 & 2.98 & 0.68 & 22.5 & 26.5 \\
\hline $\mathrm{BEL}-(21-42), \mathrm{cm}$ & 33 & $24-50$ & 31.8 & 6.00 & 0.69 & 27.7 & 35.9 \\
\hline $\mathrm{P}-<0.01 \mathrm{~mm}, \%$ & 106 & $37.7-50.6$ & 44.3 & 3.33 & 0.68 & 42.8 & 46.6 \\
\hline $\mathrm{BEL}-<0.01 \mathrm{~mm} \%$ & 24 & $36.8-60.6$ & 47.1 & 6.90 & 0.70 & 42.6 & 51.9 \\
\hline $\mathrm{P}-<0.001 \mathrm{~mm}, \%$ & 106 & $11.8-25,9$ & 19.0 & 3.38 & 0.69 & 16.7 & 21.3 \\
\hline $\mathrm{BEL}-<0.001 \mathrm{~mm} \%$ & 24 & $9.9-38.9$ & 21.5 & 7.30 & 0.70 & 16.4 & 26.6 \\
\hline $\mathrm{P}-\mathrm{pH}_{\mathrm{Kcl}}$ & 97 & $4.4-6.8$ & 5.4 & 0.52 & 0.68 & 5.05 & 5.75 \\
\hline $\mathrm{BEL}-\mathrm{pH}_{\mathrm{Kcl}}$ & 31 & $4.9-6.5$ & 5.5 & 0.54 & 0.69 & 5.13 & 5.87 \\
\hline \multicolumn{8}{|c|}{ Stable properties } \\
\hline $\mathrm{P}-$ humus, $\%$ & 99 & $2.8-6.2$ & 4.0 & 0.76 & 0.68 & 3.48 & 4.52 \\
\hline BEL-humus, $\%$ & 40 & $1.0-3.8$ & 2.3 & 0.79 & 0.69 & 1.66 & 2.84 \\
\hline $\mathrm{P}-\mathrm{S} \mathrm{mmol} / 100 \mathrm{~g}$ & 91 & $17.7-39.2$ & 25.4 & 4.8 & 0.68 & 22.1 & 28.7 \\
\hline $\mathrm{BEL}-\mathrm{S} \mathrm{mmol} / 100 \mathrm{~g}$ & 39 & $16.8-41.8$ & 25.1 & 6.4 & 0.69 & 21.0 & 29.2 \\
\hline $\mathrm{P}-\mathrm{Hr} \mathrm{mmol} / 100 \mathrm{~g}$ & 66 & $0.7-8.1$ & 3.4 & 1.58 & 0.68 & 3.3 & 4.5 \\
\hline $\mathrm{BEL}-\mathrm{Hr} \mathrm{mmol} / 100 \mathrm{~g}$ & 21 & $0.5-4.2$ & 2.3 & 1.07 & 0.70 & 1.5 & 3.1 \\
\hline
\end{tabular}

The silt fraction of the arable horizon has a similar distribution in these horizons.

In the arable horizon, $\mathrm{pH}$ values characterize a mildly acidic environment (5.1-5.5) and a partially neutral reaction environment (5.6-6.0), with a range of indicators for the entire sample of 4.4-6.8 and typical values of 5.05-5.75. In the sub-arable horizon, there is a slight increase in $\mathrm{pH}$.

In gray forest arable soils, the humus content has significantly increased, the arithmetic mean is $4.0 \%$, and the range of variation is $2.8-6.2 \%$. Typical values of this property have a narrow limit - 3.48-4.32\%. In General, these data correspond to optimal values for humus content. In the sub-arable horizon, the range of limit values of the sample expands slightly, it is more noticeable, relative to the typical values, 1.66-2.84\%.

The sum of the absorbed bases is $25.1-25.4 \mathrm{mmol}$ $1100 \mathrm{~g}$ of soil, and the hydrolytic acidity is 2.3 to $3.4 \mathrm{mmol} / 100 \mathrm{~g}$ of soil. At the same time, there is a tendency to increase the saturation of the cation exchange capacity below the arable horizon.

The observed regularities in humus content tend to change the $\mathrm{pH}$, and the saturation of the cation exchange capacity indicates the role of both the natural zonal factor, on the one hand, and the role of economic activity, on the other. The statistical parameters of grey forest soils already show traces of the process of cultivation of these soils.

\section{Conclusion}

Agro-gray soils are a typical subtype of gray soils, respectively, the average values of humus content, the amount of absorbed bases, and the $\mathrm{pH}$ of the soil suspension are typical.

The statistical data of morphometry and soil properties of the considered subtype of gray soils correspond to the main regularities and are characteristic of the current state in the conditions of anthropogenic impact. In conditions of intensive agriculture, statistical parameters make it possible to purposefully manage soil fertility in the studied region.

Statistical parameters allow you to follow the processes of soil formation in detail and accurately. Among them, the most important are the arithmetic averages that characterize the soil as a natural body.

Other statistical parameters of soils reflect the conditions of their formation in the sample, while characterizing the accuracy of obtaining arithmetic mean characteristics and properties.

\section{References}

1. V.D. Tonkonogov, I.I. Lebedeva, M.I. Gerasimova, Basic horizon-profile forming processes in Russian soils, In Soil-forming processes (Dokuchaev Soil Institute, Moscow, 2006) pp. 13-37

2. M.Y. Mikhailova, I.P. Talanov, Cultivation of corn hybrids on the expected nutritional background in the Volga region of the Republic of Tatarstan, IOP Conf. Ser. Earth and Environ. Sci., 341, 012008 (2019)

3. E.A. Dmitriev, Mathematical Statistics in Soil Science (LIBROKOM, Moscow, 2019) 334 p.

4. I.D. Davlyatshin, L.G. Gaffarova, Agrochemical properties of light gray forest soils and productivity of winter rye, Agroch. Gazette, 6, 7-9 (2016)

5. I.D. Davlyatshin, M.Yu. Gilyazov, A.A. Lukmanov et al., Handbook of agrochemists (MedDoc Ltd., Kazan, 2013) 300 p.

6. P.A. Chekmarev, A.A. Lukmanov, I.D. Davlyashin et al., Directory of the agrochemist of the Republic of Tatarstan (IE Sheikhutdinova A.I., Kazan, 2015) $322 \mathrm{p}$.

7. B.M. Kogut, Evaluation of humus content in arable soils of Russia, Soil sci., 9, 944-952 (2012)

8. L.G. Gaffarova, S.G. Murtazina, M.G. Murtazin, Dynamics of the humus state of gray forest soils of the Predkamye of the Republic of Tatarstan and the 
productivity of crop rotation with long-term fertilizer, Grain econ. of Russ., 2(50), 57-60 (2017)

9. L.L. Shishov, V.D. Tonkonogov, I.I. Lebedeva, M.I. Gerasimova, Classification and diagnostics of soils in Russia (Oykumena, Smolensk, 2004) 342 p.

10. I.D. Davlyatshin, L.G. Gaffarova, Dynamics of Light-Gray Forest Soils Agrochemical Properties in the Conditions of Agrogenesis, IOP Conf. Ser. Earth and Environ. Sci., 272, 03209 (2019)
11. A.V. Koloskova, S.M. Gilyazova, A.Kh. Sakaeva, The humus state of the soils of the Volga-Kama forest-steppe (Publ. House of Kazan Univer., 1985) $137 \mathrm{p}$.

12. A.B. Alexandrova, N.A. Berezhnaya, B.R. Grigoryan, D.V. Ivanov, V.I. Kulagina, Red book of soils of the Republic of Tatarstan (Folio, Kazan, 2012) 192 p. 